\title{
НЕЙРОПСИХОЛОГИЧЕСКАЯ КОРРЕКЦИЯ ПЕРВОКЛАССНИКОВ С ДИАГНОЗОМ НЕЙРОСЕНСОРНАЯ ПОТЕРЯ СЛУХА, ОБУЧАЮЩИХСЯ ПО СИСТЕМЕ ИНКЛЮЗИВНОГО ОБРАЗОВАНИЯ
}

\section{Сенченко Г.В., Лазарян В.В., Сенченко А.Ю.}

Одной из наиболее распространенных групп детей с ОВЗ составляют дети с нарушениями слуха. Начало учебы в школе для слабосльшашего ребенка требует дополнительных усилий по его адаптации как со стороны самого ребенка, так и со стороны педагогов и родителей. В статье представлены результаты нейропсихологической диагностики высших психических функций детей с диагнозом нейросенсорная потеря слуха (Н90), обучающихся в 1-ом классе по системе инклюзивного образования.

Цель. Оченка уровня развития высших психических функиий первоклассников с нейросенсорной потерей слуха до и после проведения программы нейропсихологической коррекиии.

Материалы и методы исследования. В исследовании приняли участие 16 первоклассников, которым выставлен диагноз нейросенсорная потеря слуха, из них 11 мальчиков (68,8\%) и 5 девочек (31,2\%) в возрасте 8-9 лет. Нейропсихологическая диагностика детей проводилась с использованием нейропсихологического альбома Ж.М. Глозман и А.Е. Соболевой. Диагностика проводилось до и после проведения программы нейропсихологической коррекции.

Результаты. При первичной диагностике детей выявлено: нарушение слухоречевой памяти; нарушение акустического гнозиса; нарушение квазипространсвенного представления и др. С учётом нейропсихологических особенностей этих детей мы разработали для них коррекиионную программу. У первоклассников с нарушением слуха, прошедших нейропсихологическую коррекиию отмечается: 
улучшение в ориентирование в собственной личности и окружающем мире, улучшение динамического праксиса и праксиса поз, улучшение зрительного восприятия и понимания логико-грамматических конструкций, предложных конструкиий, повысилась продуктивность запоминания, стало доступнее обобщение и решение задач.

Выводы. 1. Первоклассники с диагнозом нейросенсорная потеря слуха, имеют отставания в развитии ВПФ. 2. Программа нейропсихологической коррекиии направлена не только на развитие нарушенных ВПФ, но и на увеличение адаптационных возможностей детей с нарушением слуха. 3. У детей, прошедших нейропсихологическую коррекцию, выявлено значительное улучшение в пробах и уровне усвояемости школьной программы.

Область применения результатов. Результаты исследования могут быть использовань в работе педагогов и психологов, чья деятельность связана с обучением слабосльшаших детей.

Ключевые слова: инклюзивное образование; нейросенсорная потеря слуха; дети с ограниченныли возможностями здоровья; нейропсихологическая диагностика; нейропсихологическая коррекиия; высшие психические функиии.

\section{NEUROPSYCHOLOGICAL CORRECTION OF FIRST-GRADERS DIAGNOSED WITH NEUROSENSORY HEARING LOSS, STUDYING IN THE SYSTEM OF INCLUSIVE EDUCATION}

\section{Senchenko G.V., Lazaryan V.V., Senchenko A.Yu.}

One of the most common groups of children with disabilities is children with hearing impairments. A hearing-impaired child requires additional efforts to adapt, both on the part of the child himself, and on the part of teachers and parents. The article presents the results of neuropsychological diagnostics of higher mental functions of children with the diagnosis of sensorineural hearing loss (H90), studying in the 1st grade in the system of inclusive education. 
Purpose. Assessment of the level of development of higher mental functions (HMF) of first-graders with sensorineural hearing loss before and after the program of neuropsychological correction.

Materials and methods of research. The study involved 16 first-graders who were diagnosed with sensorineural hearing loss, including 11 boys (68.8\%) and 5 girls (31.2\%) aged 8-9 years. Neuropsychological diagnostics of children was carried out using the neuropsychological album of Zh.M. Glozman and A. E. Soboleva. The diagnosis was carried out before and after the neuropsychological correction program.

Results. The primary diagnosis of children revealed: violation of auditory-speech memory; disorders of acoustic gnosis; disorders of quasi-spatial vision, etc. Taking into account the neuropsychological characteristics of these children, we have developed a correctional program for them. First-graders with hearing impairment who have undergone neuropsychological correction are noted to have improved orientation in their own personality and the world around them, improved dynamic praxis and praxis of postures, improved visual perception and understanding of logical-grammatical constructions, prepositional constructions, increased memorization productivity, and more accessible generalization and problem solving.

Conclusions. 1. First-graders with a diagnosis of sensorineural hearing loss have delays in the development of HMF. 2. The program of neuropsychological correction is aimed not only at the development of HMF, but also at increasing the adaptive capabilities of children with hearing impairment. 3. Children who underwent neuropsychological correction showed a significant improvement in tests and the level of assimilation of the school curriculum.

Practical implications. The results of the study can be used in the work of teachers and psychologists whose activities are related to the training of hard-of-hearing children.

Keywords: inclusive education; sensorineural hearing loss; children with disabilities; neuropsychological diagnosis; neuropsychological correction; higher mental functions. 


\section{Актуальность}

Одной из самых актуальных проблем конца XX - начала XXI веков стало неуклонное увеличение числа детей с нарушениями в развитии. Согласно статистической информации в последние десятилетия в мире отмечается нарастание частоты рождения детей с врожденными физическими аномалиями, дефектами интеллекта и тяжелыми хроническими инвалидизирующими заболеваниями, достигающее в настоящее время 6-9\% среди новорожденных. Только частота детской инвалидности с ОВ3 за последние двадцать лет в нашей стране увеличилась в 12 раз. По прогнозам, уже в ближайшие десять лет, число таких детей достигнет 1,2-1,5 млн. человек [16]. Наличие дефектов у таких детей, оказывает влияние на становление личности, зачастую приводя к различным аспектам социальной дезадаптации [20].

Одной из наиболее распространенных групп детей с ОВЗ составляют дети с нарушениями слуха [13]. Несмотря на то, что психическое развитие таких детей подчиняется тем же закономерностям, которое характерно для детей с нормальным слухом [20], в процессе взросления они сталкиваются с рядом трудностей: когнитивными, поведенческими, эмоциональными и социальными проблемами $[4,5,7,25,27]$.

Одним из оптимальных стратегических направлений в решении проблем обучения детей с ОВ3 выступает инклюзивное образование - процесс совместного обучения и воспитания детей с ограничениями здоровья и не имеющих таких ограничений - посредством создания дополнительных специализированных условий $[1,9,12$, $14,16,18,22,26]$. При чем, обучение детей с нарушением слуха должно сочетаться с лечебно-коррекционным воздействием [10, 20].

Начало учебы в школе для слабослышащего ребенка требует дополнительных усилий по его адаптации как со стороны самого ребенка, так и со стороны педагогов и родителей $[4,11,23,24]$. Как отмечает Н.А. Пешкова трудности в адаптации в школе слабослышашего первоклассника обусловлены в первую очередь с недостаточной развитостью коммуникативных навыков ребенка, обусловленной нарушением слуха и недоразвитием речи [19]. 
Изучая психологические особенности первоклассников с нарушениями слуха в период адаптации, В.В. Банчикова отмечает, что такие дети по сравнению со сверстниками имеют сниженную учебную активность, хуже усваивают школьную программу, однако более усидчивы и дисциплинированы на уроках, инфантильны, неуверенные в себе, подчиняемы, тревожны [6].

В настоящее время, одним из ведущих методов, позволяющих повысить эффективность коррекционной работы с такими детьми и адаптацию их в школе, учитывающих индивидуальные особенности развития, является нейропсихологическая диагностика. Она позволяет выявить актуальный уровень развития высших психических функций и определить зоны ближайшего развития ребенка. Методологической основой нейропсихологического исследования являлись разработанные А. Р. Лурия теория системной динамической локализации ВПФ и принцип синдромного анализа нарушений высших психических функций $[2,15]$. Использование нейропсихологической диагностики и нейропсихологической коррекции поможет специалистам эффективнее работать с детьми, имеющими нарушения слуха.

Целью исследования является оценка уровня развития высших психических функций первоклассников с нейросенсорной потерей слуха до и после проведения программы нейропсихологической коррекции.

\section{Характеристика выборки и методы исследования}

Исследование проводилось на базе общеобразовательной школы №17 г. Красноярска, в которой внедрено и проводится обучение детей с ОВ3 по адаптированной основной общеобразовательной программе, в т.ч. и для детей с нарушением слуха.

В исследовании приняли участие 16 первоклассников, которым выставлен диагноз нейросенсорная потеря слуха (Н90). Из них 11 мальчиков $(68,8 \%)$ и 5 девочек $(31,2 \%)$ в возрасте от 8 до 9 лет. Все школьники участвовали в исследовании добровольно, при информированном добровольном согласии родителей. 
Для проведения исследования был использован нейропсихологический альбом Ж.М. Глозман, А.Е. Соболева [8]. Все диагностические методики отвечают логике и целям нашего исследования, подобраны с учетом возраста испытуемых и позволяют в совокупности выявить актуальный уровень развития высших психических функций (ВПФ) у детей.

Батарея диагностического материала разделяется по основным блокам:

1. Общая характеристика ребёнка

2. Исследование движений и действий

3. Исследование гнозиса

4. Исследование речевых функций

5. Исследование памяти

6. Исследование интеллекта

Оценка результатов осуществлялась с помощью бальной системы: 0 - безошибочное выполнение задания (норма);

0,5 - отвечает на вопросы не уверенно, ошибается, но сам исправляет ошибки без наводящих вопросов (норма);

1 - единичные ошибки, корригируемые при помощи психолога (лёгкие нарушения);

1,5 - множественные ошибки с частичной коррекцией при интенсивной помощи исследователя: вербальной регуляции, или сопряженном выполнении (умеренные нарушения);

2 - наличие ошибок, которые не полностью корригируются при внешней организации деятельности ребёнка (умеренно-выраженные нарушения);

3 - невозможность выполнения задания (выраженные нарушения).

После проведения нейропсихологической диагностики и анализа полученных результатов, родителям детей с нарушениями слуха было предложено проведение нейропсихологических коррекционных занятий. Родители восьми детей дали согласие на проведение коррекционных занятий.

Таким образом, нами были сформированы экспериментальная и контрольная группы, куда вошли дети с наличием схожих нейро- 
динамических нарушений. Однако разграничивающим фактором стало согласие родителей на проведение диагностических и коррекционных мероприятий в экспериментальной группе и только диагностических - в контрольной.

После проведения курса коррекционных нейропсихологических занятий, вновь была проведена нейропсихологическая диагностика детей из обеих групп.

\section{Результаты первичной нейропсихологической диагностики}

В результате проведения первичной нейропсихологической диагностики были выявлены особенности развития высших психических функций и составлены индивидуальные профили развития детей. В соответствии с выбранной методикой оценки развития высших психических функций у детей, показатель нормы соответствует 0 баллов. Полученные результаты оценки ВПФ, говорят о задержке их развития у всех обследованных первоклассников, имеющих нарушения слуха (рис. 1).

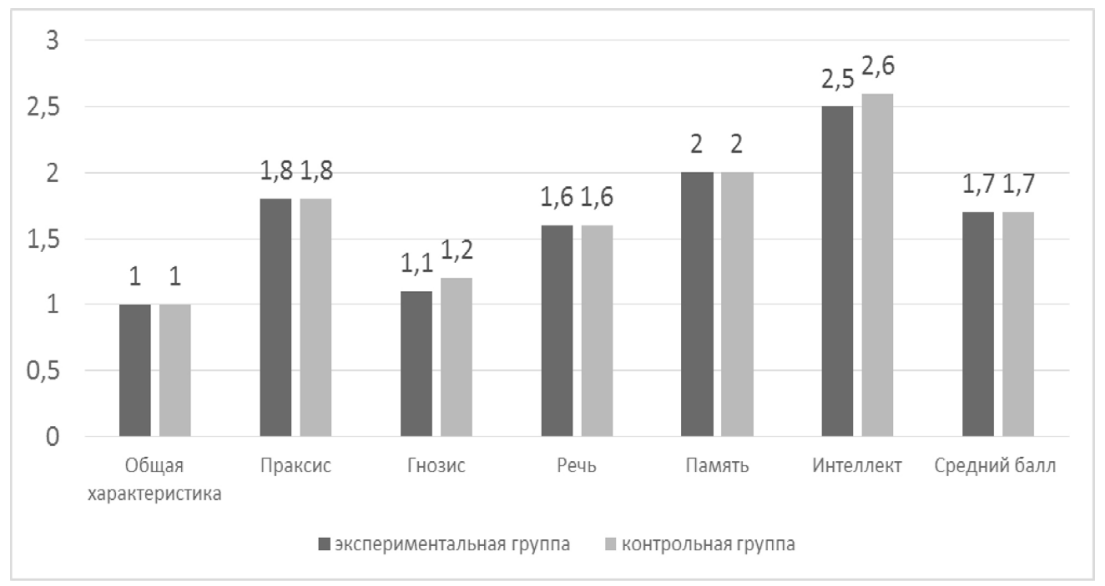

Рис. 1. Результаты первичной нейропсихологической диагностики первоклассников, имеющих нарушения слуха, в баллах

Наиболее грубо нарушенными оказались процессы интеллектуальных операций, мнестические процессы и праксис. 
Средний балл у детей, вошедших в экспериментальную группу, составил $1,68 \pm 0,2$, в контрольной $-1,71 \pm 0,17$ балла. Различия между показателями групп статистически не значимы $(\mathrm{p}=0,91)$.

Нами установлены следующие особенности психического профиля первоклассников, имеющих нарушения слуха:

- нарушение слухоречевой памяти в виде низкой мнестической продуктивности, флуктуации объема заучивания в разных предъявлениях, снижение максимального объема запоминания на 7-8 элементов по сравнению с возрастной нормой, низкая устойчивость следов памяти и интерференции;

- нарушение акустического гнозиса;

- нарушение квазипространсвенного представления: трудности понимания логико-грамматических конструкций, предложных конструкций;

- снижение динамического праксиса в виде упрощения программы, нарушения последовательности движений при самостоятельном выполнении;

- нарушение реципрокной координации через соскальзывание на одноименные движения при самостоятельном выполнении;

- недоступность экспрессивной речи.

Учитывая это нами была разработана коррекционная нейропсихологическая программа для таких детей.

Особенности коррекционной программы, направленной на преодоление нейродинамических нарушений первоклассников с диагнозом нейросенсорная потеря слуха, обучающихся по системе инклюзивного образования.

Программа предназначена для проведения коррекционно-развивающих и профилактических занятий с детьми 8-9 лет, имеющих нарушения слуха.

Цель: коррекция нейродинамических нарушений, а также сопутствующих дефектов адаптации первоклассников, с диагнозом нейросенсорная потеря слуха.

Задачи:

- Улучшение показателей произвольного внимания

- Формирование импрессивной речи 
- Увеличение словарного запаса

- Улучшение показателей мыслительной и мнестической деятельности

- Улучшение уровня адаптации детей среди сверстников

- Стабилизация и оптимизация общего тонуса организма

На каждом нейропсихологическом занятии закладывается основа для формирующего воздействия на ряд психических сфер, и создаются благоприятные условия для расширения межфункционального взаимодействия и образования новых психологических и функциональных систем.

При структурировании занятий учитывался возраст участников программы. Предложенные игры и упражнения рассчитаны на младший школьный возраст и соответствуют специфике развития детей данной категории.

В программу были включены следующие методы:

1. дыхательные упражнения В.С. Колгановой, Е.В. Пивоварова;

2. массаж «Волшебные точки»;

3. упражнения на развитие ВПФ;

4. упражнения на коммуникативные навыки и социализацию.

Коррекционная программа состоит из 10 индивидуальных 2 раза в неделю с каждым ребенком контрольной группы и 14 групповых занятий 1 раз в неделю. Групповые и индивидуальные занятия проходили параллельно. Кроме того, проводились индивидуальные домашние задания, которые ребенок может выполнять совместно с взрослым или самостоятельно.

Образец групповых занятий:

1. Разминка

Дети свободно двигаются по залу под музыку. Как только музыка прекратится, дети застывают на месте.

2. Зоопарк -1

Дети ходят, изображая косолапого мишку (на внешней стороне стопы), птенчика (на мысочках), уточку (на пяточках), неуклюжего пингвина (на внутренней стороне стопы).

3. Фокус 
Сначала дети стоят, потом просим переключить свое внимание: правая кисть, мочка левого уха и т.д.

4. Стоп-игра 1

Дети находятся на своих местах им дается команда (хлопок). Услышав команду, дети начинают свободно бегать по залу. Затем звучит вторая команда (2 хлопка). Услышав ее, дети занимают своим места в зале.

5. Преобрази фигуру

Ребенку предлагается ряд фигур. Надо зачеркнуть круг, подчеркнуть треугольник, а в квадрате поставить точку. Затем ребенку предлагается бланк с некоторым кол-вом данных фигур. Его задача - по памяти преобразовать все фигуры.

6. Поручение

Психолог просит ребенка сказать другому ребенку принести ему несколько предметов (ручка, ластик, блокнот, точилку).

7. Какие бывают профессии?

Обсудить какие есть профессии, чем они занимаются и какими инструментами, предметами пользуются.

ДОМАШНЕЕ ЗАДАНИЕ - нарисовать профессию родителей.

Образец индивидуальных занятий:

1. Дыхательные упражнения

Ребенок лежит на спине, руки и ноги лежат прямо. Не скрещиваются. По команде взрослого ребенок делает вдох через нос, выдох через широко открытый рот.

2. Глазодвигательные упражнения

ИП лежа на спине, голова фиксирована. Взрослый берет небольшой предмет и плавно водит предметом слева-направо и в обратном направлении, вверх-вниз и к носу (ребенок должен смотреть на предмет обоими глазами, не поворачивая голову, когда предмет оказывается у носа, глаза должны сходиться к переносице). Упражнение выполняется сначала на вытянутой руки ребенка, на расстоянии локтя, ладони.

\section{3. Качалка}

ИП ребенок сидит, обхватив согнутые ноги руками, затем откатывается назад, ложась на спину и возвращается в ИП. 
4. Лодочка

Ребенок ложится на живот, руки вытягивает вперед, поднимает прямые ноги. По команде взрослого он должен прогнуться и покачаться в таком положении.

5. Пальчик-мальчик

Пальчик-мальчик, где ты был?

С этим братцем в лес ходил.

С этим братцем щи варил,

С этим братцем кашу ел,

С этим братцем песни пел.

6. Семафор

Ребенок проговаривает гласные с движением рук:

А - руки вверх

О - руки вперед

У - руки в стороны

Э- руки вдоль тела

Ы - руки сложены в замок за спиной

И - руки сложить в замок на голове.

7. Запомни и найди пары слов

Ребенок должен запомнить несколько слов предъявленные парами.

Кошка-молоко

Мальчик-машина

Стол-пирог

Ручка-бумага

Лошадь-трава

8. Игра «Попробуй повторить»

По окончании коррекционной работы нами было проведено сравнение показателей нейропсихологических функций и школьной успеваемости как в экспериментальной группе детей, в которой проводилась коррекционная работа, так и в контрольной группе детей, не получавших коррекционную помощь

Средний балл в контрольной группе при повторной диагностике составил $1,56 \pm 0,15$. Средний балл в экспериментальной группе снизился до $1,23 \pm 0,19$. Снижение среднего балла произошло как в экспериментальной, так и в контрольной группе (рис. 2). 


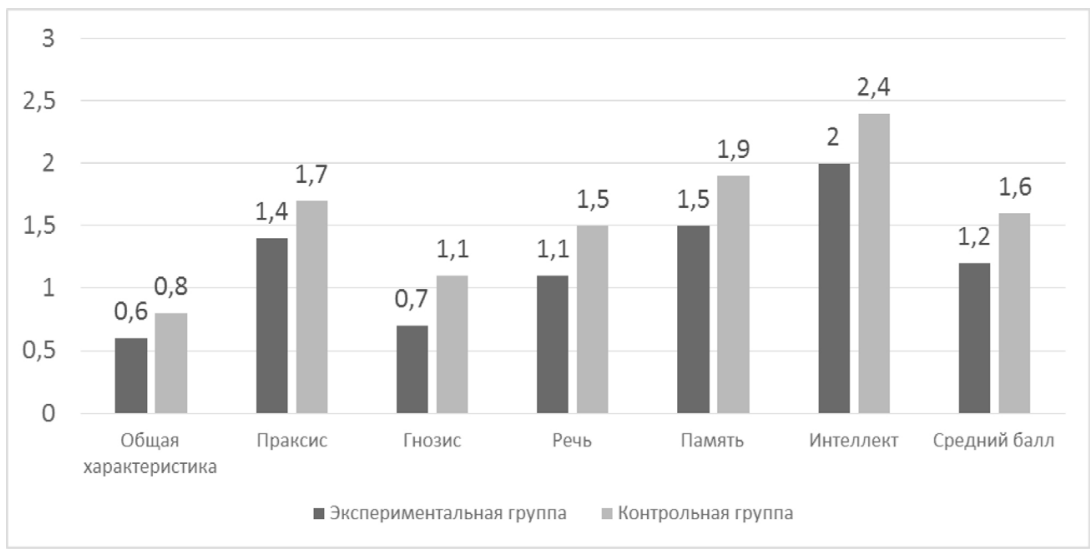

Рис. 2. Результаты повторной нейропсихологической диагностики первоклассников, имеющих нарушения слуха, в баллах

В результате коррекционной работы была получена положительная динамика оценки нейропсихологических функций среди детей экспериментальной группы:

- детям стало легче ориентироваться в месте, времени, в своих личных данных (правильно называют свой возраст, имя свое и родителей, номер и букву класса, дату и время года);

- появилась критичность к своим ошибкам (самостоятельный поиск и исправление ошибок);

- поведение и эмоциональные реакции стали адекватнее относительно ситуации (появилась понимание того как общаться со сверстниками и взрослыми, разграничение своего поведения на правила школы и дома);

- с сформировалась мотивация к занятию и выполнению домашних заданий (через дневник с наклейками);

- стали доступны методы диагностики внимания (таблица Шульте, корректурная проба осталась доступна не для всех, вызванная значительной трудности понимания инструкции и пространственными нарушениями);

- увеличился объем слухоречевой памяти (в среднем на 4 единицы); 
- увеличился словарный запас и улучшилась экспрессивная речь (дети правильно построенными предложениями отпрашиваются на занятии в туалет/попить воды, научились строить короткий рассказ про свой день, описывать свое настроение);

- улучшение показателей динамического праксиса (выполнение без упрощения программ, появилась возможность выполнения без зрительного контроля);

- улучшение адаптации детей среди сверстников и в семье (более коммуникабельные с другими детьми на перемене, улучшился контакт с родителями)

- повышение эффективности учебного процесса (в связи с возрастом нет оценочных критериев, ориентировались на проверку качества усвоения учебной программы преподавателем).

Всё выше сказанное характерно для экспериментальной группы. В контрольной группе таких изменений выявлено не было.

Учитывая, что используемая в методике нейропсихологического обследования шкала оценок представляет собой шкалу порядка, для установления достоверности различий полученных нами результатов исследования нами был применен критерий Т. Уайта. Значение этого критерия для экспериментальной группы составило Тф=46, а для контрольной - Тф=82. Значение этого критерия при 5\%-ном уровне значимости составляет Тст=49. Так как Тст $=49>\mathrm{T} \phi=46$, следует заключить, что различия между полученными результатами достоверны ( $\mathrm{T}=46$ при $\mathrm{p}<0,05)$.

По результатам проведенного нами исследования, можно сделать следующие выводы.

1. Первоклассники с диагнозом нейросенсорная потеря слуха, имеют отставания в развитии ВПФ. Наиболее выраженные нарушения отмечаются в работе произвольного внимания, импрессивной речи, мыслительной и мнестической деятельности. Такие дети нуждаются в проведении нейропсихологической коррекции.

2. Разработанная нами нейропсихологическая коррекционная программа направлена не только на развитие нарушенных ВПФ, но и на увеличение адаптационных возможностей детей с нарушением 
слуха, за счет улучшения качества развития функций, связанных с активной связной речью, увеличения словарного запаса и развития эмоционального интеллекта.

3. Эффективность нейропсихологической коррекционной программы, была подтверждена при повторной нейропсихологической диагностики. У детей из экспериментальной группы было выявлено значительное улучшение в пробах: ориентирование в собственной личности и окружающего мира, улучшение динамического праксиса и праксиса поз, улучшения зрительного восприятия и понимания логико-грамматических конструкций, предложных конструкций, продуктивность запоминания, стало доступнее обобщение и решение задач.

Информация о конфликте интересов. Авторы заявляют об отсутствии конфликта интересов.

Информация о спонсорстве. Исследование проведено без финансовой поддержки.

\section{Список литературы}

1. Алехина С.В., Алексеева М.Н., Агафонова Е.Л. Готовность педагогов как основной фактор успешности инклюзивного процесса в образовании // Психологическая наука и образование. 2011. Т. 16, № 1. C. 83-92. https://psyjournals.ru/psyedu/2011/n1/39878.shtml

2. Ардила А., Ахутина Т.В., Микадзе Ю.В. Вклад А.Р. Лурии в изучение мозговой организации языка // Неврология, нейропсихиатрия, психосоматика. 2020. Т. 12, №1. С. 4-12. https://doi.org/10.14412/20742711-2020-1-4-12

3. Бабич Е.Г., Савченко Д.В. Особенности эмоциональной сферы у детей с нарушением слуха // Научный альманах. 2017. № 1-2 (27). С. 322-325. https://doi.org/10.17117/na.2017.01.02.322

4. Бабич Е.Г., Савченко Д.В., Сагалов М.В. Социально-психологические особенности адаптации к учебной деятельности первоклассников с нарушениями слуха // Ученые записки Российского государственного социального университета. 2016. Т. 15, № 4 (137). С. 42-50. https://doi.org/10.17922/2071-5323-2016-15-4-42-50 
5. Байдина Ю.Э., Труфанова Г.К. Особенности речевого развития детей с нарушениями слуха // Science Time. 2016. № 5 (29). С. 43-47.

6. Банчикова В.В. Особенности психологической адаптации детей младшего школьного возраста с нарушением слуха в общеобразовательной школе // Психологическая студия: сборник статей студентов, магистрантов, аспирантов, молодых исследователей кафедры прикладной психологии ВГУ имени П.М. Машерова. Витебск, 2020. С. 18-20.

7. Богданова Т.Г., Томсон В.А. Проблемы изучения личности детей и подростков с нарушениями слуха в зарубежной психологии // Вопросы психологии. 2020. № 5. С. 157-167.

8. Глозман Ж.М. Нейропсихологическое обследование. Качественная и количественная оценка данных. М.: Смысл, 2012. 263 с.

9. Инклюзивное образование. Индивидуализация сопровождения детей с ограниченными возможностями здоровья: материалы Всероссийской научно-практической конференции (г. Челябинск, 9 февраля 2016 г.) / отв. за выпуск: Л.Б. Осипова, Е.В. Плотникова. Челябинск: Изд-во Челябинский государственный педагогический университет, 2016. 349 с.

10. Калыбекова С.К., Нахаева К.И., Сакибаева М.А. К вопросу обучения и воспитания детей с нарушениями слуха // Научно-практические исследования. 2019. № 8-3 (23). С. 99-103.

11. Карауш И.С., Куприянова И.Е. Особенности взаимодействия педагогов с учащимися в системе коррекционного образования // Общество: социология, психология, педагогика. 2018. № 9 (53). С. 52-56. https://doi.org/10.24158/spp.2018.9.10

12. Козырева О.А. Образование детей-инвалидов и лиц с ограниченными возможностями здоровья: учеб. пособие. Красноярск: тип. КрасГМУ, 2016. 154 с.

13. Королева И.В., Янн П.А. Дети с нарушениями слуха: Книга для родителей и педагогов. СПб: КАРО, 2011. 240 с.

14. Михальчи Е.В. Инклюзивное образование: учебник и практикум для бакалавриата и магистратуры. М.: Издательство ЮРАЙТ. 2018. 177 с.

15. Назарова Н.М. Специальная педагогика: учеб. пособие для студ. высш.учеб. заведений. М.: Издательский центр «Академия», 2010. $400 \mathrm{c}$. 
16. Неретина Т.Г., Кружилина Т.В., Орехова Т.Ф. Проблемы и перспективы развития инклюзивного образования в России // Гуманитарно-педагогические исследования. 2018. Т. 2, № 2. С. 14-23. http:// gpi.magtu.ru/images/doc/2-2018.pdf

17.Никитина Е.Л. Проблемы развития инклюзивного образования // Концепт: научно-методический электронный журнал. 2014. Т. 29. C. 31-35. https://e-koncept.ru/2014/65278.htm

18. Пешкова Н.А. Развитие межличностных отношений у слабослышащих младших школьников // Акмеология. 2016. № 1 (57). С. 155-158. http://narodnoe.org/journals/akmeologiya/2016-1/razvitie-mejlichnostnihotnosheniiy-u-slaboslishashih-mladshih-shkolnikov

19. Севастьянова У.Ю. Особенности личности как фактор дезадаптации у младших школьников с разными вариантами дизонтогенеза // Герценовские чтения: психологические исследования в образовании. 2020. № 3. C. 608-614. https://doi.org/10.33910/herzenpsyconf-2020-3-58

20. Симкин М.Л., Мальцева И.А. Развитие связной речи у детей младшего школьного возраста с нарушением слуха // Вестник Кемеровского государственного университета. Серия: Гуманитарные и общественные науки. 2020. T. 4, № 1 (13). С. 38-46.

21. Daniel G.R., McLeod S. Children with Speech Sound Disorders at School: Challenges for Children, Parents and Teachers // Australian Journal of Teacher Education, 2017, vol. 42, № 2. http://dx.doi.org/10.14221/ajte.2017v42n2.6

22. François M, Boukhris M, Noel-Petroff N. Schooling of hearing-impaired children and benefit of early diagnosis // European Annals of Oto-rhino-laryngology, Head and Neck diseases, 2015, vol. 132, №5, pp. 251255. http://dx.doi.org/10.1016/j.anorl.2015.08.026

23. Kim SJ, Kwon MS, Han W. Development of a School Adaptation Program for Elementary School Students with Hearing Impairment // Journal of Audiology \& Otology, 2015, vol. 19, №1, pp. 26-33. https://doi. org/10.7874/jao.2015.19.1.26

24. Nina J. Laugen, Karl H. Jacobsen, Carolien Rieffe \& Lars Wichstrøm. Social skills in preschool children with unilateral and mild bilateral hearing loss // Deafness \& Education International, 2017, vol. 19, №2, pp. 54-62. https://doi.org/10.1080/14643154.2017.1344366 
25. Singh S. Revisiting Inclusion of Children with Hearing Impairment: Issues and Possibilities // In: Chennat S. (eds) Disability Inclusion and Inclusive Education. Springer, Singapore. 2019. https://doi.org/10.1007/978981-15-0524-9_8

26. Stevenson J, Kreppner J, Pimperton H, Worsfold S, Kennedy C. Emotional and behavioural difficulties in children and adolescents with hearing impairment: a systematic review and meta-analysis // European Child \& Adolescent Psychiatry, 2015, vol. 24, №5, pp. 477-496. https://doi. org/10.1007/s00787-015-0697-1

\section{References}

1. Alekhina C.V., Alekseeva M.N., Agafonova E.L. Gotovnost' pedagogov kak osnovnoy faktor uspeshnosti inklyuzivnogo protsessa v obrazovanii [Preparedness of teachers as the main factor of success of the inclusive process in education]. Psikhologicheskaya nauka i obrazovanie [Psychological Science and Education], 2011, vol. 16, no. 1, pp. 83-92. https:// psyjournals.ru/psyedu/2011/n1/39878.shtml

2. Ardila A., Akhutina T.V., Mikadze Yu.V. Vklad A.R. Lurii v izuchenie mozgovoy organizatsii yazyka [A.R. Luria's contribution to studies of the brain organization of language]. Nevrologiya, neyropsikhiatriya, psikhosomatika [Neurology, Neuropsychiatry, Psychosomatics], 2020, vol. 12, no. 1, pp. 4-12. https://doi.org/10.14412/2074-2711-2020-1-4-12

3. Babich E.G., Savchenko D.V. Osobennosti emotsional'noy sfery u detey s narusheniem slukha [Features of the emotional sphere in children with hearing impairment]. Nauchnyy al'manakh [Science Almanac], 2017, no. 1-2 (27), pp. 322-325. https://doi.org/10.17117/ na.2017.01.02.322

4. Babich E.G., Savchenko D.V., Sagalov M.V. Sotsial'no-psikhologicheskie osobennosti adaptatsii k uchebnoy deyatel'nosti pervoklassnikov s narusheniyami slukha [Socio-psychological peculiarities of adaptation to educational activity of first-graders with hearing impairments]. Uchenye zapiski Rossiyskogo gosudarstvennogo sotsial'nogo universiteta [Scientific notes of the Russian state social University], 2016, vol. 15, no. 4 (137), pp. 42-50. https://doi.org/10.17922/2071-5323-2016-15-4-42-50 
5. Baydina Yu.E., Trufanova G.K. Osobennosti rechevogo razvitiya detey s narusheniyami slukha [Features of speech development in children with hearing impairments]. Science Time, 2016, no. 5 (29), pp. 43-47.

6. Banchikova V.V. Osobennosti psikhologicheskoy adaptatsii detey mladshego shkol'nogo vozrasta s narusheniem slukha v obshcheobrazovatel'noy shkole [Features of psychological adaptation of children of primary school age with hearing impairment in general education schools]. Psikhologicheskaya studiya: sbornik statey studentov, magistrantov, aspirantov, molodykh issledovateley kafedry prikladnoy psikhologii VGU imeni P.M. Masherova [Psychological Studio]. Vitebsk, 2020, pp. 18-20.

7. Bogdanova T.G., Tomson V.A. Problemy izucheniya lichnosti detey i podrostkov s narusheniyami slukha $\mathrm{v}$ zarubezhnoy psikhologii [Problems of studying the personality of children and adolescents with hearing disorders in foreign psychology]. Voprosy psikhologii [Questions of Psychology], 2020, no. 5, pp. 157-167.

8. Glozman Zh.M. Neyropsikhologicheskoe obsledovanie: kachestvennaya i kolichestvennaya otsenka dannykh [Neuropsychological examination. Qualitative and quantitative assessment of data]. M.: Smysl, 2012, $263 \mathrm{p}$.

9. Inklyuzivnoe obrazovanie. Individualizatsiya soprovozhdeniya detey s ogranichennymi vozmozhnostyami zdorov'ya [Proc. conf. "Inclusive education. Individualization of accompanying children with disabilities"]. Chelyabinsk, 2016. 349 p.

10. Kalybekova S.K., Nakhaeva K.I., Sakibaeva M.A. K voprosu obucheniya i vospitaniya detey s narusheniyami slukha [On the issue of education and upbringing of children with hearing impairments]. Nauchno-prakticheskie issledovaniya [Scientific and practical research], 2019, no. 8-3 (23), pp. 99-103.

11. Karaush I.S., Kuprijanova I.E. Osobennosti vzaimodejstvija pedagogov $\mathrm{s}$ uchashhimisja $\mathrm{v}$ sisteme korrekcionnogo obrazovanija [The aspects of the interaction between teachers and students in the special education system]. Obshhestvo: sociologija, psihologija, pedagogika [Society: Sociology, Psychology, Pedagogics], 2018, no. 9 (53), pp. 52-56. https:// doi.org/10.24158/spp.2018.9.10 
12. Kozyreva O.A. Obrazovanie detejinvalidov i lics ogranichennymi vozmozhnostjami zdorov'ja: ucheb. posobie [Education of children with disabilities and persons with disabilities]. Krasnojarsk, 2016, 154 p.

13. Koroleva I.V., Jann P.A. Deti s narushenijami sluha: Kniga dlja roditelej i pedagogov [Children with hearing impairments: A book for parents and teachers.]. SPb.: KARO, 2011, 240 p.

14. Mihal'chi E.V. Inkljuzivnoe obrazovanie: uchebnik i praktikum dlja bakalavriata i magistratury [Inclusive education: a textbook and a workshop for undergraduate and graduate studies]. M.: JuRAJT, 2018, 177 p.

15. Nazarova N.M. Special'naja pedagogika: ucheb. posobie dlja stud. vyssh.ucheb. zavedenij [Special pedagogy: textbook manual for students higher education institutions]. M.: Izdatel'skij centr «Akademija», 2010, $400 \mathrm{p}$.

16. Neretina T.G., Kruzhilina T.V., Orehova T.F. Problemy i perspektivy razvitija inkljuzivnogo obrazovanija v Rossii [Prospects and problems of inclusive education in Russia]. Gumanitarno-pedagogicheskie issledovanija [Humanitarian and pedagogical Research], 2018, vol. 2, no. 2, pp. 14-23. http://gpi.magtu.ru/images/doc/2-2018.pdf

17. Nikitina E. L. Problemy razvitija inkljuzivnogo obrazovanija [Problems of development of inclusive education]. Koncept, 2014, vol. 29, pp. 3135. https://e-koncept.ru/2014/65278.htm

18.Peshkova N.A. Razvitie mezhlichnostnyh otnoshenij u slaboslyshashhih mladshih shkol'nikov [Development of interpersonal relations among hearingimpaired junior schoolchildren]. Akmeologija, 2016, no. 1 (57), pp. 155-158. http://narodnoe.org/journals/akmeologiya/2016-1/razvitie-mejlichnostnih-otnosheniiy-u-slaboslishashih-mladshih-shkolnikov

19. Sevast'janova U.Ju. Osobennosti lichnosti kak faktor dezadaptacii u mladshih shkol'nikov s raznymi variantami dizontogeneza [Personality traits as maladjustment factors in primary school students with various disabilities]. Gercenovskie chtenija: psihologicheskie issledovanija v obrazovanii [Herzen Readings: Psychological research in education], 2020, no. 3, pp. 608-614. https://doi.org/10.33910/herzenpsyconf-2020-3-58 
20. Simkin M.L., Mal'ceva I.A. Razvitie svjaznoj rechi u detej mladshego shkol'nogo vozrasta s narusheniem sluha [Coherent speech development in primary school children with hearing impairments]. Vestnik Kemerovskogo gosudarstvennogo universiteta. Serija: Gumanitarnye $i$ obshhestvennye nauki [Bulletin of Kemerovo State University. Humanities and Social Sciences], 2020, vol. 4, no. 1 (13), pp. 38-46.

21. Daniel G.R., McLeod S. Children with Speech Sound Disorders at School: Challenges for Children, Parents and Teachers. Australian Journal of Teacher Education, 2017, vol. 42, no. 2. http://dx.doi.org/10.14221/ajte.2017v42n2.6

22. François M, Boukhris M, Noel-Petroff N. Schooling of hearing-impaired children and benefit of early diagnosis. European Annals of Oto-rhino-laryngology, Head and Neck diseases, 2015, vol. 132, no. 5, pp. 251-255. http://dx.doi.org/10.1016/j.anorl.2015.08.026

23. Kim SJ, Kwon MS, Han W. Development of a School Adaptation Program for Elementary School Students with Hearing Impairment. Journal of Audiology \& Otology, 2015, vol. 19, no. 1, pp. 26-33. https://doi. org/10.7874/jao.2015.19.1.26

24. Nina J. Laugen, Karl H. Jacobsen, Carolien Rieffe \& Lars Wichstrøm. Social skills in preschool children with unilateral and mild bilateral hearing loss. Deafness \& Education International, 2017, vol. 19, no. 2, pp. 54-62. https://doi.org/10.1080/14643154.2017.1344366

25. Singh S. Revisiting Inclusion of Children with Hearing Impairment: Issues and Possibilities. In: Chennat S. (eds) Disability Inclusion and Inclusive Education. Springer, Singapore. 2019. https://doi.org/10.1007/978-98115-0524-9_8

26. Stevenson J, Kreppner J, Pimperton H, Worsfold S, Kennedy C. Emotional and behavioural difficulties in children and adolescents with hearing impairment: a systematic review and meta-analysis. European Child \& Adolescent Psychiatry, 2015, vol. 24, no. 5, pp. 477-496. https://doi. org/10.1007/s00787-015-0697-1

\section{ДАННЫЕ ОБ АВТОРАХ}

Сенченко Галина Васильевна, преподаватель кафедры клинической психологии и психотерапии с курсом ПО 
Красноярский государственный медииинский университет имени профессора В.Ф. Войно-Ясенеикого

ул. Партизана Железняка, 1, г. Красноярск, 660022, Российская Федерации

senchenkogalina@yandex.ru

Лазарян Варсена Вановна, клинический психолог

ООО «Островок»

ул. Академика Вавилова, 25Б, г. Красноярск, 660025, Российская Федерация

mvar10@mail.ru

Сенченко Алексей Юрьевич, доцент кафедры управления и экономики здравоохранения ИПО, кандидат медицинских наук, доцент Красноярский государственный медииинский университет имени профессора В.Ф. Войно-Ясенеикого

ул. Партизана Железняка, 1, г. Красноярск, 660022, Российская Федерация

sentchenko@mail.ru

\section{DATA ABOUT THE AUTHORS}

Galina V. Senchenko, Teacher of the Department of Clinical Psychology and Psychotherapy

Krasnoyarsk State Medical University named after Professor V.F. Voino-Yasenetsky

1, Partizana Zheleznyak Str., Krasnoyarsk, 660022, Russian Federation

senchenkogalina@yandex.ru

SPIN-code: 9967-7933

ORCID: 0000-0002-1920-0710

ResearcherID: AAO-2210-2020

Varsena V. Lazarian, Clinical Psychologist

'Ostrovok' Children's Development Center 
25b, Akademik Vavilov Str., Krasnoyarsk, 660025, Russian Federation

mvar10@mail.ru

ORCID: 0000-0001-8915-1590

Alexey Yu. Senchenko, Associate Professor of the Department of Management and Economics of Healthcare, Ph.D. in Medicine Krasnoyarsk State Medical University named after Professor V.F. Voino-Yasenetsky

1, Partizana Zheleznyak Str., Krasnoyarsk, 660022, Russian Federation

sentchenko@mail.ru

SPIN-code: 9794-7985

ORCID: 0000-0002-0190-5800

ResearcherID: N-7426-2015 